1

2

3

4

5

6

7

8

9

10

11

12

\title{
Continued Increases in the Intensity of Strong Tropical Cyclones
}

\author{
James B. Elsner
}

Department of Geography

Florida State University

Tallahassee, FL 32306

Corresponding Contact Information:

jelsner@fsu.edu

$850-273-0112$ 
Using satellite derived wind speed estimates from tropical cyclones over the 25 -year period 1981--2006, Elsner et al. (2008) showed the strongest tropical cyclones getting stronger. They related the increasing intensity to rising ocean temperatures consistent with theory. Oceans continued to warm since that paper was published so the intensity of the strongest cyclones should have continued upward as well. Here I show that this is the case with increases in the upper quantile intensities of global tropical cyclones amounting to between 3.5 and $4.5 \%$ in the period $2007--2019$ relative to the earlier base period (1981--2006). All basins individually show upward intensity trends for at least one upper quantile considered with the North Atlantic and Western North Pacific basins showing the steepest and most consistent trends across the quantiles.

Capsule Summary: The strongest tropical cyclones have continued to get stronger consistent with theory and with the findings published in Elsner et al. (2008). 


\section{Forum}

Science is validated through predictions. Using satellite-derived wind speed estimates from tropical cyclones over the 26-year period between 1981 and 2006, Elsner et al. (2008) showed that the strongest tropical cyclones worldwide were getting stronger. They related this increase in tropical cyclone intensity to a corresponding rise in ocean temperatures consistent with theory (Emanuel 1988). The oceans have continued to warm since that paper was published so I would anticipate that the upward trend in the intensity of the strongest tropical cyclones has continued.

To check on this I consider all global tropical cyclones with wind speeds of at least $33 \mathrm{~m} / \mathrm{s}$ occurring over the six basins. I divide the data into two epochs; the period 1981--2006 corresponding to the years used in Elsner et al. (2008) and the period 2007--2019 corresponding to the 13 years following that publication. The data are three-hourly estimates of the wind speed maximum made by forecast operational centers and compiled by IBTraCS (Knapp et al. 2010, 2018). Note that the 'data' used in Elsner et al. (2008) are regression-estimated intensities from satellite imagery so the wind speed and trend magnitudes are not directly comparable due to the 'regression-to-the-mean' effect. However, to be consistent with the earlier work I use the single highest wind speed over the lifetime of each tropical cyclone. I compute quantile wind speeds over the two distinct epochs and quantify the change in these quantile wind speeds in terms of the percentage increase from the earlier base period (1981--2006). 
I note that the 75th percentile highest wind speed for the set of global tropical cyclones having lifetime highest wind speeds of at least $33 \mathrm{~m} / \mathrm{s}$ has increased by $4 \%$ from $61.7 \mathrm{~m} / \mathrm{s}$ during the earlier period to $64.3 \mathrm{~m} / \mathrm{s}$ during the later period. Further I note that the 90 th percentile wind speed has increased by $3.6 \%$ and the 95 th percentile wind speed has increased by $4.3 \%$ from $72 \mathrm{~m} / \mathrm{s}$ during the earlier period to $75.2 \mathrm{~m} / \mathrm{s}$ over the later period. All six basins individually show upward intensity trends for at least one upper quantile with the North Atlantic and Western North Pacific basins showing the steepest and also the most consistent trends across the spread of quantiles examined (Figure 1).

For example, the 95th percentile wind speed for the set of Western North Pacific typhoons increased by $6.4 \%$ from $74.6 \mathrm{~m} / \mathrm{s}$ during the earlier period to $79.7 \mathrm{~m} / \mathrm{s}$ during the later period. While the 95 th percentile wind speed for the set of North Atlantic hurricanes increased by $4.8 \%$ from $72 \mathrm{~m} / \mathrm{s}$ during the earlier period to $75.6 \mathrm{~m} / \mathrm{s}$ during the later period. The largest percentage increase across the basins and quantiles is $7.4 \%$ for the 75 th percentile wind speed over the Western North Pacific. The largest percentage increase in the Southern Hemisphere is $5.4 \%$ for the 75 th percentile wind speed over the South Pacific. The inter-basin differences in percent increases are not large and no basin shows a significant change (at the $\alpha=.001$ level) in the number of cyclones reaching at least $33 \mathrm{~m} / \mathrm{s}$ between the two epochs although the Western North Pacific had three fewer typhoons per year on average during the latest epoch.

This post-publication analysis shows a continued increase in the intensity of the strongest hurricanes worldwide as first identified in Elsner et al. (2008) using data only through 2006. The results were anticipated given the continued heating of the tropical oceans (Cheng et al. 2018) although other 
factors like tropopause temperature changes and changes in the amount of wind shear also play a role making it difficult to anticipate near-future changes on the time scale of a few years.

\section{References}

Elsner, James B., James P. Kossin, and Thomas H. Jagger. 2008. "The Increasing Intensity of the Strongest Tropical Cyclones.” Nature 455 (7209): 92-95.

Emanuel, Kerry A. 1988. "The Maximum Intensity of Hurricanes.” Journal of the Atmospheric Sciences 45 (7): 1143-55.

Knapp, K. R., M. C. Kruk, D. H. Levinson, H. J. Diamond, and C. J. Neumann. 2010. “The International Best Track Archive for Climate Stewardship (IBTrACS): Unifying tropical cyclone best track data." Bulletin of the American Meteorological Society 91: 363-376.

Knapp, K. R., H. J. Diamond, J. P. Kossin, M. C. Kruk, C. J. Schreck. 2018.

“International Best Track Archive for Climate Stewardship (IBTrACS) Project, Version 4. [WP, NP, $N A, S I, N I, S P] . ”$ NOAA National Centers for Environmental Information. 정 https://doi.org/10.25921/82ty-9e16 [Accessed March 1, 2020]. 
Western North Pacific Typhoons

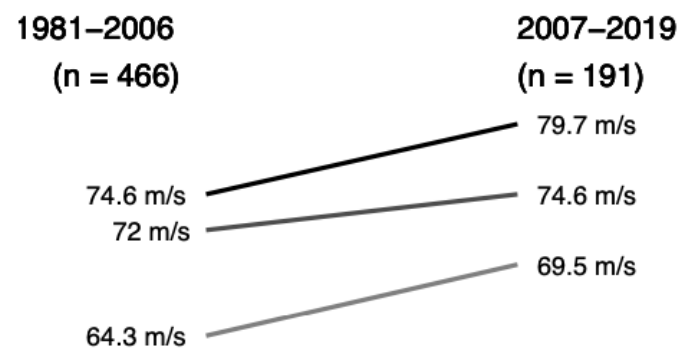

Southern Indian Cyclones

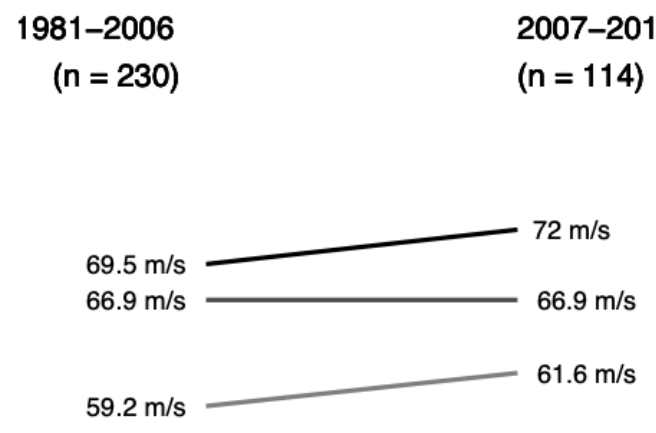

South Pacific Cyclones

1981-2006

( $n=147)$ 2007-2019

$(n=56)$

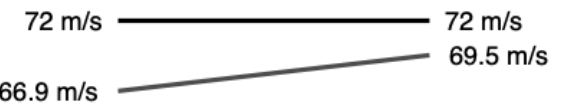

$56.6 \mathrm{~m} / \mathrm{s}$

$59.8 \mathrm{~m} / \mathrm{s}$
Eastern North Pacific Hurricanes

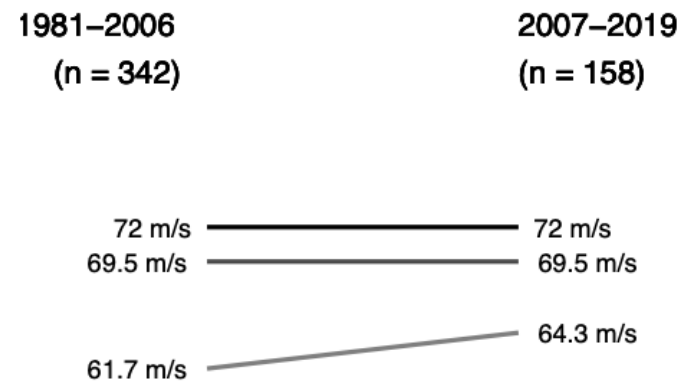

North Atlantic Hurricanes

$\begin{array}{cl}1981-2006 & 2007-2019 \\ (n=165) & (n=93)\end{array}$

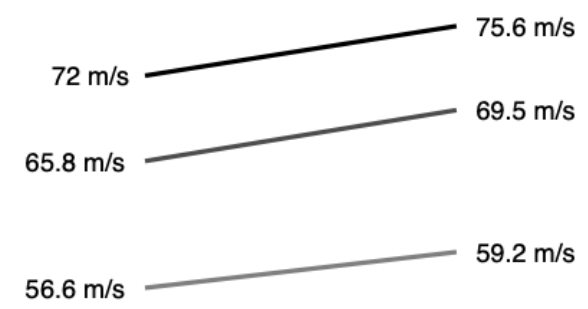

Northern Indian Cyclones

$\begin{array}{cl}1981-2006 & 2007-2019 \\ (n=54) & (n=31)\end{array}$

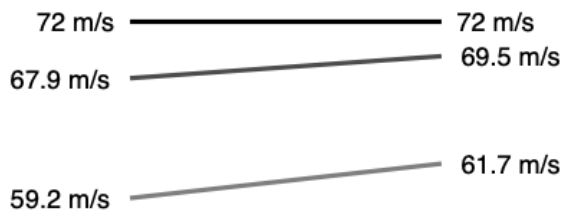


Figure 1: Percentile wind speeds in two distinct epochs by major tropical cyclone basins. The epoch years (chosen based on the pre and post Elsner et al. (2008) study) and the number of tropical cyclones with lifetime highest wind speeds of at least $33 \mathrm{~m} / \mathrm{s}(\mathrm{n})$ are shown at the top of the left and right columns. The wind speeds corresponding to the 75 th, 90th, and 95th percentiles are given in the respective columns below each epoch. The changes are noted by the slope of the line segments colored by percentiles (75th in light gray, 90th in gray, and 95th in black). The vertical scales are the same across the basin. 